\title{
Catadores de Materiais Recicláveis no Município de Cerro Largo (RS): perspectivas através do trabalho e o papel da ITCEES - UFFS (Incubadora Tecnossocial de Cooperativas e Empreendimentos de Economia Solidária) ${ }^{1}$
}

\author{
Louise de Lira Roedel Botelhol ${ }^{2}$ \\ Luciana Scherer ${ }^{3}$ \\ Jorge Adalberto Schommer ${ }^{4}$ \\ Helena Diecheti ${ }^{5}$ \\ Artur Filipe Ewald Wuerges ${ }^{6}$
}

\begin{abstract}
Resumo
Esta reflexão teórico-metodológica visa compreender a vida e o trabalho dos catadores de materiais recicláveis no município de Cerro Largo, RS, e qual a relação destes com a atuação das ITCPs (Incubadoras Tecnológicas de Cooperativas Populares) no seu papel de articuladoras do desenvolvimento. As ITCPs estão vinculadas às universidades, e seu objetivo principal é desenvolver e disseminar conhecimentos sobre cooperativismo, autogestão, gestão social e economia solidária, contribuindo para o desenvolvimento local e regional do espaço onde estão inseridas. Embora existam na literatura corrente trabalhos e relatos de experiências das ITCPs com catadores, ainda se demonstra carência na compreensão qualitativa da evolução do trabalho e da vida desses catadores em relação à atuação da incubadora. Nesse sentido, o presente trabalho aposta no uso da abordagem interpretativa e tem seu foco central na dinâmica e multidimensionalidade do fenômeno, sofrendo influências de várias frentes e com vários reflexos diferentes. As dimensões estudadas neste trabalho serão duas: os catadores e a ITCP, sendo que a ideia central é que o estudo possibilite compreender como essas dimensões interagem entre si. Neste trabalho, serão investigados cinco catadores, objetivando-se analisar o trabalho das ITCPs e como elas auxiliam na melhoria da qualidade de vida dos investigados. Espera-se que este estudo permita o surgimento de
\end{abstract}

\footnotetext{
${ }^{1}$ Financiado pelo CNPq.

${ }^{2}$ Doutora em Engenharia e Gestão do Conhecimento. Administradora e Mestre em Engenharia e Gestão do Conhecimento. Professora na Universidade Federal da Fronteira Sul (UFFS), Campus Cerro Largo. louisebotelho@uffs.edu.br

${ }^{3}$ Doutoranda em Desenvolvimento Regional na Universidade Regional do Noroeste do Estado do Rio Grande do Sul (Unijuí). Administradora e Bacharel em Turismo. Mestre em Ciências Sociais. lucianascherer@yahoo.com.br

${ }^{4}$ Mestrando em Desenvolvimento e Políticas Públicas na Universidade Federal da Fronteira Sul (UFFS), Campus Cerro Largo. Administrador. jorge@agaltur.com.br

${ }^{5}$ Graduanda em Administração na Universidade Federal da Fronteira Sul (UFFS), Campus Cerro Largo. helenadicheti@live.com

${ }^{6}$ Doutorando em Administração na Universidade Federal da Fronteira Sul (UFFS). Administrador e Mestre em Administração. Professor na UFFS, Campus Cerro Largo. artur.wuerges@uffs.edu.br
} 
novos conhecimentos, encaminhamentos e pesquisas sobre desenvolvimento.

Palavras-chaves: ITCPs. Catadores. Desenvolvimento. Sustentabilidade. Gestão Social.

\begin{abstract}
This theoretical and methodological reflection aims to understand the life and labor of the collectors of recyclable materials in the city of Cerro Largo, RS, and how they relate to the performance of ITCPs (Technological Incubators of Popular Cooperatives) in their role of articulators of development. ITCPs are linked to universities, and their main objective is to develop and disseminate knowledge about cooperativism, self-management, social management and solidarity economy, contributing to the local and regional development of the space where they are inserted. Although there are current literature and reports on the experiences of ITCPs with waste collectors, there is still a lack in the qualitative understanding of the evolution of work and life of these scavengers in relation to the incubator's performance. In this sense, the present work bets on the use of the interpretative approach and has its central focus on the dynamics and multidimensional of the phenomenon, suffering influences of several fronts and with several different reflexes. The dimensions studied in this work will be two: the collectors and the ITCPS, and the central idea is that the study makes it possible to understand how these dimensions interact with each other. In this work, five tasters will be investigated, aiming to analyze the work of ITCPs and how they help improve the quality of life of the investigated. It is hoped that this study will allow the emergence of new knowledge, referrals and research on development.
\end{abstract}

Keywords: Collectors. Development. Sustainability. Social Management.

\title{
1 Introdução
}

Uma das atividades mais antigas presentes na história da humanidade é a de catar restos de alimentos para sobreviver. Com o tempo, essa atividade foi ganhando outros contornos, transformando-se em mais do que uma prática de sobrevivência: adquiriu o formato de trabalho, gerando renda para parte da população geralmente marginalizada. Hoje, a indústria da reciclagem é ampla e promissora, porém os atores diretos desse importante mecanismo econômico, os catadores, ainda são prejudicados nos vários âmbitos que permeiam essa atividade, tanto econômico, como social, cultural e psíquico. A mudança no modo de vida da sociedade, o desenvolvimento tecnológico e o consumismo alteraram as formas de consumo da população, alcançando padrões insustentáveis com a cultura do "produto descartável", que é considerado prático e moderno (LOPES, 2006). Esses fatores aumentaram a capacidade geradora de resíduos sólidos da população e se tornaram um problema nas cidades.

Nas palavras de Almeida (2008), a reciclagem envolve três etapas: recu- 
peração, que engloba os processos de separação dos resíduos na fonte, coleta seletiva, prensagem, enfardamento; revalorização, que compreende os processos de beneficiamento dos materiais, como a moagem e a extrusão, e, por fim, a transformação, que é a reciclagem propriamente dita, transformando os materiais recuperados e revalorizados em um novo produto.

Segundo Bortoli (2008), a profissão de catador de material reciclável foi reconhecida e oficializada, em 2002, pela Classificação Brasileira de Ocupações (CBO). Desde então, várias políticas públicas de inclusão de catadores e de financiamentos, visando ao fortalecimento e à sustentabilidade das organizações de catadores, têm sido viabilizadas. A partir daí o gerenciamento dos Resíduos Sólidos Urbanos (RSU) é responsabilidade da administração pública municipal. Todavia, até os dias de hoje, muitas prefeituras ainda não conseguiram organizarse frente às dificuldades operacionais, financeiras e de controle existentes para a categorização do lixo produzido no município (GONÇALVES, 2012).

Importante destacar ainda que o trabalho desses atores sociais e ambientais agrega aos resíduos sólidos mais do que valor econômico, insere também valor social e ambiental. Assim, sua importância vem crescendo ao longo dos tempos em vista da construção de uma sociedade sustentável. Todavia, os "catadores" ainda são "[...] marcados pela exploração do trabalho frente aos atravessadores. Esta situação mantém os catadores vulneráveis, dependentes dos compradores, vulneráveis socialmente e ainda pouco organizados" (SILVA; DENARDI; BERNO, 2015).

A Lei 12.305, de 02 de agosto de 2010, que institui o Plano Nacional de Resíduos Sólidos - PNRS, prioriza a implantação da coleta seletiva nos municípios, por meio do Plano Municipal de Gestão Integrada de Resíduos Sólidos (PMGIRS), com a participação de cooperativas, ou outras formas de associação de catadores de materiais reutilizáveis e recicláveis, formadas por pessoas físicas de baixa renda.

Assim, as Incubadoras Tecnológicas de Cooperativas Populares (ITCPs) constituem-se num importante instrumento de união entre a sociedade e os catadores de materiais recicláveis, inserindo-os na sociedade como indivíduos plenos. As incubadoras tiveram seu início no ano de 1995, por meio de uma demanda de um grupo da sociedade civil denominado Comitê de Entidades no Combate à Fome e pela Vida. Essa organização, liderada pelo sociólogo Herbert de Souza, estruturou-se, juntamente com a Coordenação dos Programas de Pós-graduação em Engenharia da Universidade Federal do Rio de Janeiro (COPPE/UFRJ), a fim de construir uma metodologia de incubação para o cooperativismo popular e, assim, difundi-la por outras universidades do país (REZENDE; BOEIRA, 2014). Em 1998, 14 ITCPs resolveram se organizar em rede com o objetivo de instituir um processo intenso de troca de conhecimentos e colaboração mútua (SINGER, 2000, p.130). Atualmente, houve uma ampliação da Rede de ITCPs, da qual fazem parte hoje cerca de 54 incubadoras.

As ITCPs buscam articular multidisciplinarmente áreas de conhecimento de universidades brasileiras com grupos populares interessados em gerar traba- 
Iho e renda, visando contribuir na formação de cooperativas populares e/ou empresas autogestionárias. Sua atuação se dá em um duplo sentido: na formação dos estudantes, por meio da vinculação do ensino, da pesquisa e da extensão, e na geração de trabalho e renda (GUERRA, 2008). O seu trabalho está voltado para o processo educativo por intermédio da cooperação e da autogestão, constituindo-se como projetos, programas ou órgãos das universidades.

Para efetivar a atuação das ITCPs com os grupos beneficiários, nesse caso os empreendimentos incubados, há o processo chamado incubação ${ }^{7}$. Geralmente envolve desde o primeiro contato, a sua aceitação, formação, assessoria e acompanhamento até sua saída da ITCP (desincubação). A metodologia de incubação pode ser vista como um processo educativo (PEREIRA, 2007), dialógico, participativo, emancipatório ou de gestão e assessoramento (BOTELHO et al., 2013).

A metodologia de incubação é embasada, fundamentalmente, em dois eixos de atuação: o primeiro deles relacionado aos princípios da cooperação, da autogestão e do desenvolvimento da capacidade emancipatória dos incubados; o segundo eixo é relacionado à viabilidade econômica, composto por administração, produção e comercialização, inserção produtiva, educação e capacitação profissional. Carvalho e Cançado (2009) afirmam que o processo de incubação busca promover a autossustentabilidade dessas organizações. Torna-se um instrumento educativo/pedagógico gerador de diversos tipos de conhecimentos, dentre eles, o de gestão.

Mas por que a escolha das incubadoras tecnológicas de cooperativas populares como parte e instrumento do objeto de estudo? As incubadoras são, em sua maioria, órgãos ligados a diversas universidades do país, que têm por objetivo utilizar os recursos humanos e os conhecimentos da universidade na formação, qualificação e assessoria de trabalhadores, para a construção de atividades autogestionárias, visando à sua inclusão no mercado de trabalho (GUIMARÃES, 1999).

Para os pesquisadores, as ITCPs são propícias ao desenvolvimento de modelos de gestão alternativos, pois: (i) desenvolvem projetos de pesquisas e estudos relacionados à Economia Solidária; (ii) a maior parte do conteúdo dos cursos de formação técnica são referentes às atividades administrativas; (iii) criam seus próprios materiais didáticos utilizados nos cursos de formação; (iv) apresentam profissionais capacitados nas atividades de incubação (docentes, discentes, pesquisadores e técnicos); e (v) apresentam diversas experiências nas incubações de empreendimentos solidários nos moldes autogestionários.

Nesse sentido, as ITCPs formam um ambiente propício para o estudo de práticas de gestão social, principalmente no tocante à implementação do Plano Nacional de Resíduos Sólidos - PNRS, pois estimulam a construção do conhecimento por meio de suas atuações com os grupos beneficiários (catadores) e a sociedade. A coevolução da tríade catadores - ITCPs - sociedade (políticas pú-

\footnotetext{
7 Salienta-se que os catadores de resíduos sólidos urbanos não estão incubados na ITCEES. Para a realização do processo de incubação, é necessária a realização de chamada pública via edital para seleção dos incubados, que necessariamente devem estar legalizados em Organização/Associação sem fins lucrativos.
} 
blicas) é possível somente através de novas abordagens teóricas e práticas, que estimulem e apoiem o processo de desenvolvimento dessa atividade.

A ITCEES analisada neste estudo está instalada no município de Cerro Largo, mais precisamente na Universidade Federal da Fronteira Sul. Este município, pertencente à região das Missões, no noroeste do Rio Grande do Sul, e tem a agricultura como carro-chefe da economia. A chamada modernização da agricultura fez com que o trabalho assalariado e de meeiros fosse substituído pelas máquinas. As crises na economia, as estiagens, a queda dos preços dos produtos agrícolas e o avanço tecnológico levaram grande número de trabalhadores ao desemprego, e alguns encontraram na coleta de materiais recicláveis uma alternativa de renda.

De acordo com Boff (2012), a região das Missões corresponde a 4,6\% do território do estado e é constituída de 25 municípios, na maioria de pequeno porte e de perfil predominantemente rural, com baixas taxas de urbanização. 0 uso do solo na região é baseado principalmente no cultivo de soja, milho, trigo, mandioca, cana-de-açúcar e na criação de bovinos e suínos.

Os municípios que geravam os maiores volumes de resíduos sólidos urbanos em 1996, eram Santo Ângelo, São Luiz Gonzaga e Giruá. A região produzia cerca de 40.556 ton/ano, sendo que desse total, Santo Ângelo contribuía com 12.954 ton/ano ou 35,5t/dia; São Luiz Gonzaga, com 6.902 ton/ano ou 18,9 ton/ dia, e Giruá com 3.427 ton/ano ou 9,4 ton/dia. Na região missioneira, são poucos os municípios que vêm desenvolvendo a coleta seletiva de resíduos, apenas os municípios de Santo Ângelo, São Luiz Gonzaga, Giruá e Porto Xavier praticam essa atividade e contam com unidades de triagem de resíduos ou usinas de reciclagem. Alguns destes municípios também registram a presença de trabalhadores organizados na forma de cooperativas e/ou associações de catadores e/ou recicladores.

No Rio Grande do Sul, dos 496 municípios do estado, apenas 57 contam com a presença de catadores nas ações de coleta seletiva, sendo que 38 estão organizados em associações ou cooperativas (PNSB, 2008). Dessa maneira, o presente trabalho fará um estudo interpretativo envolvendo os catadores de resíduos sólidos no município de Cerro Largo (RS). A ITCP a ser analisada é a ITCEES - Incubadora Tecnossocial de Cooperativas e Empreendimentos Econômicos Solidários, a ITCP mais recente em relação à experiência de trabalho com catadores. Nessa perspectiva, este artigo objetiva discutir até que ponto essa incubadora social oportuniza ganhos e benefícios para os catadores de materiais recicláveis.

\section{Metodologia}

A metodologia utilizada neste trabalho é descritiva, interpretativa e de cunho fenomenológico. A pesquisa interpretativa, segundo Gil (2010), tem por objetivo relacionar o que o autor afirma com o problema para o qual se propõe uma solução. Na leitura interpretativa, procura-se conferir significado mais amplo aos resultados obtidos com a leitura analítica. 
Segundo Gil (2010), a pesquisa fenomenológica busca a interpretação do mundo através da consciência do sujeito formulada com base em suas experiências. Seu objeto é, portanto, o próprio fenômeno tal como se apresenta à consciência, ou seja, o que aparece, e não o que se pensa ou se afirma a seu respeito. Tudo, pois, tem que ser estudado tal como é para o sujeito, sem interferência de qualquer regra de observação. Para a fenomenologia, um objeto pode ser uma coisa concreta, mas também uma sensação, uma recordação, não importando se este constitui uma realidade ou uma aparência.

\subsection{Delineamento do estudo}

Esta pesquisa está baseada num modelo paradigmático de Burrell e Morgan (1979). Para tanto, utilizou-se o olhar interpretativo da realidade. Nesse modelo, os autores apresentam quatro paradigmas, cada qual contemplando um conjunto de pressupostos teóricos. Esses quatro paradigmas são o funcionalista, o interpretativo, o humanista radical e o estruturalista radical, desencadeando diferentes correntes e abordagens de pesquisa.

Para tanto, pontua-se neste trabalho o segundo paradigma, ou seja, o interpretativo, já que nele a realidade é um produto das experiências subjetivas e intersubjetivas dos indivíduos (MORGAN, 1980). Outro motivo que induziu à escolha do segundo paradigma é a percepção dos participantes sobre os fenômenos sociais, já que esse paradigma se fundamenta na perspectiva dos participantes investigados.

Parafraseando Merriam (1998), o esclarecimento da posição do investigador é um dos fatores que pode assegurar a confiança de uma pesquisa qualitativa, já que tem por base tentar compreender um fenômeno social. A pesquisa interpretativa procura desvendar significados atribuídos pelas pessoas sobre o alicerce de suas experiências, buscando compreender como esse fenômeno social ocorre. Esse tipo de abordagem assemelha-se a um grande guarda-chuva, cujo princípio é regido pelo entendimento do fenômeno social (MERRIAM, 1998).

\subsection{Estratégia de pesquisa}

Em relação à estratégia de pesquisa, empregou-se o estudo de caso, com a intenção de conhecer a vida dos catadores de materiais recicláveis no município de Cerro Largo.

Merriam (1998) argumenta que, no estudo de caso, o interesse está no processo e não nos resultados, como é a proposta desta pesquisa. Assim, a autora mostra que a importância desse procedimento está no contexto e não numa variável específica.

Nesse modelo, há uma delimitação prévia do que ou quem será estudado, ou seja, delimita-se o caso. Assim, existe a presença de uma unidade, com imposição de limites para a execução do estudo. Gil (2002) argumenta que esse procedimento consiste em um estudo profundo e exaustivo de um ou poucos objetos, 
de maneira que permita seu amplo e detalhado conhecimento.

\subsection{Coleta de dados}

Como instrumento de coleta de dados, foram utilizadas as entrevistas com cinco catadores de materiais recicláveis, os quais residem em Cerro Largo. Após a sondagem e avaliação de quem são e onde vivem os catadores desse município, por meio de conversas informais com moradores de diversos bairros, identificouse uma espécie de cluster, agrupamento dos catadores em determinado local do município, que será contemplado com maior detalhamento nas análises destes estudos. Foram agendadas entrevistas com cinco catadores, e criou-se um roteiro para sua condução, que tinha como proposta identificar cinco pontos principais: a) a vida pessoal dessas pessoas e a sua relação com a sociedade; b) a percepção da sociedade em relação à profissão de catador; c) a percepção do catador em relação à estrutura e às políticas públicas do município para com o processo reciclagem; d) a compreensão das formas de trabalho em grupo (cooperativismo e associativismo); e) a relação entre ITCPs e os catadores do município de Cerro Largo.

\subsection{Organização e análise dos dados}

A análise dos dados foi realizada no período entre fevereiro e maio de 2016. Essa análise se baseou no modelo de três estágios de Milles e Huberman (1994), que incluem:

1. Redução dos dados coletados: envolve a identificação, a codificação e a classificação dos dados em categorias;

2. Exibição dos dados: envolve a realização de resumos e a catalogação das informações para, posteriormente, agrupá-las em temas;

3. Verificação: envolve a interpretação dos dados, a construção das primeiras conclusões e a verificação dos significados.

Ressalta-se que a postura metodológica deste estudo também diz respeito a sua cuidadosa realização, especialmente em relação às generalizações, ou seja, aqui a intenção metodológica é realmente conhecer os casos estudados, para, a partir daí, possibilitar que, futuramente, estudos mais generalizáveis sobre o fenômeno em questão possam ser realizados.

\section{A ITCEES - Incubadora Tecnossocial de Cooperativas e Empreendimentos de Economia Solidária da UFFS}

A Universidade Federal da Fronteira Sul (UFFS) foi concebida em 2009, a partir de um processo histórico de mobilização de diversos segmentos sociais, com a característica singular de promover a cultura da participação e construção coletiva no seu processo de consolidação. A instituição busca atender, portanto, 
uma região historicamente excluída do processo de desenvolvimento econômico e social, tendo como missão interiorizar o ensino universitário público, oportunizando o desenvolvimento regional integrado das cidades e estados que compõem a grande fronteira do MERCOSUL e seu entorno (TREVISOL; CORDEIRO; HAAS, 2011). A UFFS possui seis campi instalados na fronteira oeste dos estados do Rio Grande do Sul (RS), Santa Catarina (SC) e Paraná (PR): Cerro Largo, Erechim e Passo Fundo, no Rio Grande do Sul; Laranjeiras do Sul e Realeza, no Paraná (PR), e a sede em Chapecó, em Santa Catarina. A área de abrangência da UFFS - Campus Cerro Largo - compreende as regiões das Missões, Celeiro, Noroeste Colonial e Fronteira Noroeste do Rio Grande do Sul.

No ano de 2013, a Incubadora Tecnossocial de Empreendimentos de Economia Solidária da UFFS (ITCEES) Campus Cerro Largo, constituiu-se inicialmente via projeto de extensão, por meio de aprovação em edital do Programa de Extensão Universitária (PROEXT) 2014/MEC/SESU, que possibilitou os recursos necessários para a sua formação e institucionalização. Posteriormente, por intermédio de editais internos da própria UFFS e aprovação em Chamada do MCTI - Ministério da Ciência, Tecnologia e Inovação e SENAES Secretaria Nacional de Economia Solidária, nas chamadas MCTI/SECIS /TEM /SENAES /CNPq no 89/2013 e UNIVERSAL - MCTI/ CNPq n 14/2014, a ITCEES foi oficializada. Então, a sua institucionalização se efetivou com a aprovação do Regimento Interno pelo Conselho do Campus Cerro Largo, o que possibilitou a sua transformação de projeto de extensão em Laboratório do Campus Cerro Largo, garantindo, assim, o seu funcionamento no longo prazo. Atualmente, a ITCEES faz parte do grupo de incubadoras sociais do Programa Nacional de Incubadoras Tecnológicas de Cooperativas Populares (RONINC) do Governo Federal, e ganhou destaque nacional por sua atuação na assessoria de cooperativas de agricultura familiar nas regiões das Missões, Celeiro, Noroeste Colonial e Fronteira Noroeste no Rio Grande do Sul.

A ITCEES é um local para o desenvolvimento de ações de incubação e cooperação em cooperativas e empreendimentos econômicos solidários. Ela atua através de ações de pesquisa e extensão, prestando assessoria técnica e social aos empreendimentos incubados. O trabalho da ITCEES, de forma mais ampla, atua também na promoção de um espaço de estudos e pesquisa-ação. A incubadora volta-se para a promoção de um ambiente que estimule no aluno a troca de conhecimentos diretos com professores, técnicos e sociedade. Para tanto, nela já foram promovidos trabalhos de conclusão de cursos, programas de estágios com os incubados, projetos de dissertações, artigos científicos, livros, entre outros. A ITCEES possui linhas de atuação de pesquisa e extensão, decorrentes das demandas da sociedade, como, no caso, o trabalho nas escolas, no qual se promovem palestras e cursos com alunos do primeiro e segundo graus sobre cooperativismo e economia solidária. Tudo isso tendo em vista uma preocupação com a construção de um mundo melhor para as próximas gerações.

Uma ação desenvolvida muito importante, que justamente diz respeito a este estudo, é a atuação da ITCEES junto a um grupo de catadores de materiais recicláveis do município de Cerro Largo- RS. Essa frente está pautada no fomento 
ao trabalho organizativo e associativo dos catadores, salientando-se que o objetivo principal é organizar a associação desses catadores para que o município consiga regularizar o espaço destinado à coleta de resíduos sólidos, bem como a implantação, em Cerro Largo, da coleta seletiva de lixo. Além disso, almeja-se que, com esse trabalho desenvolvido pela incubadora, os catadores adquiram autoestima e vislumbrem e compreendam sua importância na sociedade e para as gerações futuras.

Por tudo isso, a ITCEES atua como um lócus de promoção e disseminação do conhecimento junto à sociedade. A meta final da incubadora é continuar seu trabalho com vistas à construção de um mundo melhor para as gerações de hoje e de amanhã por meio de suas ações. Seu trabalho tem foco na solidariedade e cooperação entre professores, técnicos, alunos, comunidade, incubados, movimentos sociais, clubes de serviços, associações, entre outros.

\section{Gestão social e desenvolvimento - os pressupostos teóricos que embasam a atuação da ITCEES}

Os referenciais teóricos que guiam a ITCEES - Campus Cerro Largo - estão alicerçados nos pressupostos teórico-metodológicos de gestão social discutidos por Tenório (1998; 2005), França Filho (2007) e Cançado (2011). A gestão social vem apresentando, nos últimos anos, um gradativo aumento da visibilidade junto a abordagens organizacionais. Embora ainda embrionária na academia brasileira (BOULLOSA; SCHOMMER, 2009; FISCHER, 2002), sendo vista de várias formas (CANÇADO, 2011), apresenta algumas possibilidades interessantes tanto na concepção de processo gerencial como de finalidade de atuação nas problemáticas da sociedade. Embora esse termo pareça apresentar um quase intuitivo entendimento, quase tautológico, tanto no sentido de remeter a políticas e processos sociais, ou mesmo, à participação de pessoas no processo de gestão, faz-se necessário aprofundar alguns entendimentos e escolhas teórico-metodológicas, no sentido de se buscar maior clareza sobre o que se está abordando. Se por um lado tal abordagem possa ser intuitiva, por outro, é bastante simplista, o que muitas vezes leva a uma generalização e a uma certa banalização, no sentido de que tudo que seria uma gestão "diferente", seria uma gestão social (CANÇADO, 2011). O primeiro ponto a ser considerado é que a gestão social não diz respeito apenas às políticas e ações sociais no âmbito do estado. Nesse sentido, Carrion (2007) chama atenção para o cuidado de não se confundir gestão social com gestão do "social", ou seja, quando se aborda gestão social, não se está falando em uma transposição de técnicas de negócios para o social. O outro cuidado é que não se deve pensar que gestão social é aquela que envolve pessoas, pois, assim, qualquer gestão seria social (hoje), uma vez que não é possível pensar gestão sem o envolvimento de pessoas (FRANÇA FILHO, 2008).

Ainda, seguindo na linha de se entender a gestão social no âmbito das ações da ITCEES, o termo gestão social acaba confundindo-se com a própria ideia de gestão pública. Isto porque a gestão das demandas e necessidades do social 
sempre foi atribuição típica do estado na modernidade, através das chamadas políticas públicas, especialmente as políticas sociais. Mas se pode entender também que questões sociais não são de exclusividade do estado. Nessa ideia, concentra-se o trabalho desenvolvido pela ITCEES: no entendimento de que, para além do estado, a gestão das demandas e necessidades do social pode ocorrer via sociedade, por meio das suas mais diversas formas e mecanismos de auto-organização, especialmente do fenômeno associativo (FRANÇA FILHO, 2008).

Muito embora a ITCEES esteja estabelecida em âmbito público, a sua atuação extrapola a ação de política social, já que é pautada em uma proposta de extensão, de troca de saberes, de utilização de conhecimento e de estímulos à organização cooperativa e associativa entre público e privado, para propiciar a meIhoria de vida do público envolvido, seja em termos sociais, econômicos, culturais e ambientais. Ainda segundo França Filho (2008), existe uma dinâmica política de auto-organização social, por meio da utilização de distintas formas e concepções associativas, cujo papel deve ser valorizado caso se pretenda alcançar uma real democratização da sociedade.

Tenório (1998) assevera que, na gestão social, a autoridade, para a tomada de decisões, é partilhada por todos que participam da ação, onde quer que ela ocorra, seja em organizações públicas, privadas ou não-governamentais, constituindo-se, pois, um processo gerencial que se dá de maneira dialógica. Entendese ainda que essas discussões sobre gestão social permitem analisar elementos da relação estado-sociedade e capital-trabalho. Esses pares de palavras dão sentido a uma série de fenômenos políticos, sociais e econômicos por eles gerados, e o autor propõe, para as discussões sobre gestão social, uma inversão nos termos que formam os pares de palavras: sociedade-estado e trabalho-capital.

A nova ordem nas palavras é construída de forma proposital para trazer a sociedade e o trabalho como protagonistas nos processos de construção da cidadania. Tratar a sociedade como prioridade frente ao estado, e o trabalho frente ao capital é uma escolha metodológica que faz todo o sentido para as ações da ITCEES, que entende justamente que a sociedade e o trabalhador são os que precisam de fortalecimento como agentes e destinatários finais das mudanças que envolvem as ordens política, social, econômica e ambiental.

Outra abordagem importante que orienta as ações e escolhas ITCEES é o entendimento da gestão social como forma de condução de processos. Para isso, recorre-se a uma segunda ideia, na qual Tenório (2005) pauta seus delineamentos sobre a gestão social: o confronto ao conceito de gestão estratégica, polaridade essa entendida como um ponto de partida para demarcar ambos os conceitos. Para Tenório (1998, p. 15), a gestão estratégica é “[...] um tipo de ação social utilitarista, fundada no cálculo de meios e fins e implementada através da interação de duas ou mais pessoas na qual uma delas tem autoridade formal sobre a(s) outra(s)", enquanto a gestão social é 
[...] acorde com o agir comunicativo, dialógico, a verdade só existe se todos os participantes da ação social admitem sua validade, isto é, verdade é a promessa de consenso racional, ou a verdade não é uma relação entre o indivíduo e a sua percepção do mundo, mas sim um acordo alcançado por meio da discussão crítica, da apreciação intersubjetiva (TENÓRIO, 1998, p. 17).

Assim, o argumento de que gestão social, num primeiro momento, poderia ser entendida como aquela em que há participação de pessoas, mostra-se insuficiente e requer, então, um posicionamento sobre a forma de se fazer gestão. Se pautada pela relação estado-sociedade e capital-trabalho, onde estado e capital são protagonistas, pela lógica de mercado, em uma perspectiva liberal e que visa ao lucro econômico, está-se falando em gestão estratégica. Por outro lado, se pautada pela relação sociedade-estado e trabalho-capital, onde sociedade e trabalho prevalecem como protagonistas, pela lógica do diálogo, da participação, da solidariedade e do empoderamento de atores sociais em vulnerabilidade (especificamente nesse caso), está-se falando em gestão social.

Outro aspecto bastante importante no contexto aqui tratado é o fato de que a relação entre os participantes de uma discussão é bastante afetada pelo grau de escolaridade desses participantes, existindo a possibilidade de que os que detêm maior "conhecimento" acabarem estabelecendo uma relação de poder sobre os demais (TENÓRIO, 2005). Em análises sobre os cenários que fazem a gestão social, Tenório (1990) traz uma reflexão bastante pertinente sobre a relação da ITCEES com os catadores, a partir do entendimento de que qualquer que seja a relação social, haverá duas possibilidades no uso do conhecimento: a direção, apontando o que é certo e o que é errado, e a discussão dos saberes.

Ao se tratar uma relação entre universidade e atores sociais, os quais, de forma geral, encontram-se em situação de vulnerabilidade econômica, social e ambiental, há que se ter em mente que as "escolaridades" serão bastante ímpares, já que se relacionam graduados, mestres e doutores - no âmbito da universidade -, e pessoas com uma baixa escolaridade e conhecimento técnicocientífico-cultural bastante fragilizado. O desafio está em construir uma relação participativa, com conhecimentos convergentes: o saber de quem estudou deve ser usado como apoio às discussões, mas não como orientador primeiro e único na decisão.

Entende-se que em uma relação coletiva como essa que se pretende construir entre a universidade e os catadores o poder se dilui entre os participantes, já que o conhecimento e as informações são compartilhados. Se, por um lado, a universidade apresenta saberes técnico-científicos, os catadores apresentam o conhecimento adquirido a partir da sua experiência e da sua vivência dos problemas tratados, não existindo donos da verdade, nem pressupostos que não possam ser discutidos de forma ampla e generalizada.

Essa postura de reconhecimento de todos os saberes traz a possibilidade de se desenvolver, na prática, o conceito de cidadania deliberativa, discutida por Habermas e entendida por Tenório (2008) com a legitimidade das decisões, as quais devem ter origem em processos de discussão orientados pelos princípios 
da inclusão, da igualdade participativa, da autonomia e do bem comum. Com esse propósito, a gestão social estaria capacitada a servir como elo entre a sociedade civil organizada, o estado e o mercado, sendo a protagonista primeira da relação. Seria, assim, um processo participativo, baseado no diálogo e na inclusão.

\section{A visão dos entrevistados sobre o papel da ITCEES: perspectivas e trabalho}

O objetivo do presente estudo está focado em entender as expectativas e as perspectivas dos catadores de Cerro Largo em relação à ITCEES e as suas possibilidades de geração de ações que visem à inclusão e ao desenvolvimento, assim como ao conhecimento das características deste grupo: quem são, como vivem e quais são suas dificuldades e seus anseios, para que, a partir do conhecimento dessas realidades, seja possível uma real intervenção.

Para tanto, foram selecionados pelos autores cinco eixos fundamentais que serviram de roteiro para as cinco entrevistas realizadas. A seguir, apresentam-se os resultados divididos pelos eixos norteadores:

a) Histórico da vida dos catadores de material reciclado do município de Cerro Largo (dados pessoais e econômicos)

A faixa etária dos entrevistados variou entre 30 e 55 anos, o que propiciou uma amplitude significativa e, portanto, realidades e vivências diferenciadas. É importante destacar que todos os investigados possuem no mínimo sete anos de experiência, sendo que alguns iniciaram suas atividades com 17 anos.

Identificado um agrupamento de catadores e recicladores de Cerro Largo, procedeu-se a entrevista. Todos os entrevistados residiam no mesmo bairro, já que os catadores que permanecem na atividade há mais tempo estão localizados todos no mesmo bairro. Em relação à renda familiar, nas cinco famílias, encontrou-se a reciclagem como renda principal, mesmo que outros membros da família tenham outros trabalhos ou recebam benefícios. Em via de regra, a "outra renda" é uma renda complementar àquela obtida na atividade de catadores de resíduo sólido. Este fato aumenta significativamente a necessidade de uma meIhora na produção tanto em relação à qualidade da estrutura quanto a valores econômicos e sociais. Os entrevistados moram em grupos familiares cujo número de integrantes varia entre três e sete pessoas.

b) A percepção da sociedade em relação à profissão de catador de material reciclável

Todos os entrevistados, como já mencionado acima, possuem um longo tempo de experiência como catadores. Alguns começaram ainda jovens, com 17 anos, porém todos já têm mais de 7 anos como catadores de material reciclado. Esse período foi todo vivenciado em Cerro Largo, com exceção de uma entrevistada que, por um certo período, trabalhou com o esposo em Porto Alegre, em uma cooperativa de catadores. 
Normalmente se interessam em seguir esta profissão por influências familiares ou de amigos próximos (vizinhos). Essa é uma das razões da formação de um tipo de cluster. Outro fator determinante para seguirem esta profissão, identificado sobretudo entre os mais novos, é a falta de outra oportunidade profissional, relacionada às condições sociais (estudo e origem social, por exemplo), como afirma uma das entrevistadas: "Não tinha muito estudo, não tinha emprego e estava difícil. Aí comecei a catar material".

Percebe-se que, independente dos motivos que os levaram a ser catadores e recicladores, todos têm orgulho e muito prazer no que fazem. É muito presente essa sensação quando observadas as suas falas: "Trabalho digno", "Sintome muito feliz", "Gosto muito do que eu faço".

Por outro lado, nota-se que os catadores percebem que seu trabalho não é valorizado pela sociedade. Quando questionados se já sofreram algum tipo de coerção ou preconceito, todos são unânimes em afirmar que sim. Algumas expressões fazem-nos refletir sobre o olhar da sociedade para com esta classe trabalhadora: "Olha lá uma guria juntando lixo". Parte do preconceito é associado ao fato de algumas pessoas, ao recolherem os materiais recicláveis, não tomarem o cuidado de fechar novamente os sacos de lixo:

[...] o pessoal reclama quando mexemos nas lixeiras porque alguns rasgam as sacolas e bagunçam, e aí o pessoal pensa que são todos assim. Outras vezes, nas ruas, quando a gente já vai descendo e a gente vê uma sacolinha com algum material, garrafa plástica, o pessoal grita 'Oh, tu, não me rasga o lixo!'.

A hostilidade contra o grupo, muitas vezes, não é expressa em palavras: "Às vezes, não precisa falar nada. Apenas o jeito como olham para a gente, com nojo, isso já é um preconceito". Outra entrevistada apresentou uma visão crítica a respeito de seu trabalho e do preconceito sofrido: "O pessoal acha que a gente está necessitada, mas não se dão conta de que estamos ajudando a sociedade e a natureza".

Outro ponto abordado neste tema foram as ferramentas disponíveis para o trabalho. Todos se utilizam de uma "gaiota" puxada a cavalo, um tipo de carroça, e é apenas com isso e a "força de vontade" que acabam realizando a coleta e posterior seleção do material.

c) A percepção do catador em relação à estrutura e às políticas públicas do município para com o processo de reciclagem

Quando interrogados sobre as condições de trabalho em Cerro Largo, é notório que apresentam um forte apego ao município e, por isso, todos se dizem satisfeitos. Porém, quando perguntados sobre os limites estruturais e o apoio do governo local, são unânimes em relatar a falta de apoio da sociedade como um todo, iniciando pela separação do lixo nas residências, que quase nunca é realizada pelos moradores desse município. Vejamos uma fala de um dos entrevistados: "O povo deve se organizar melhor, saber separar. Mesmo tendo campanha, o 
povo não funcionou. O trânsito, o pessoal acha a gente um estorvo. Esses dias quase deu acidente".

Os catadores relatam que, muitas vezes, encontram cacos de vidros misturados com o material reciclável e que precisam cuidar para não se cortarem. Assim como há muito lixo úmido misturado com lixo seco, perdendo-se grande parte do material que poderia ser transformado em renda.

Em relação à administração pública municipal, o principal problema está na falta de um trabalho conjunto entre os catadores e aqueles que coletam o lixo, que, no caso de Cerro Largo, é realizado pela prefeitura. Outro ponto importante e mais urgente levantado por quase todos os entrevistados é a necessidade de um local apropriado para depositarem o material coletado e realizarem a separação e seleção. Necessitam de um espaço que lhes permita trabalhar independentemente das condições climáticas e que lhes proporcione segurança para estocar o material até ser vendido. Hoje esses processos são realizados em terrenos desocupados próximos a suas casas, provocando, de certo modo, um acúmulo de sujeira, pois nem todo material coletado acaba sendo aproveitado. Além disso, muitas vezes, precisam guardar o material em casa, para garantir que não seja roubado. Os materiais geralmente são plásticos, papelão e sucatas.

d) A compreensão das formas de trabalho em grupo (cooperativismo e associativismo)

Quando perguntados sobre a organização atual, todos responderam que realizam a coleta e a seleção individualmente. Perguntou-se sobre a existência de competição entre eles, e a resposta foi que sim, porém todos se respeitam, por mais que eventualmente acabem existindo alguns desentendimentos casuais e momentâneos.

Em relação ao trabalho coletivo através de uma associação ou cooperativa, alguns são resistentes, pois, na experiência anterior com a Associação dos Catadores em Cerro Largo, as relações e processos de governança não foram bem conduzidos. Percebe-se um certo receio quanto ao trabalho em grupo, mas, na maioria, todos já tiverem experiências coletivas. O que todos destacam como principais problemas são a má gestão e a falta de transparência na contabilidade da Associação. Contudo, percebe-se que estão conscientes de que se organizando por meio de uma associação ou cooperativa, conseguirão ser mais fortes e, com certeza, terão uma renda maior, conforme a fala de um dos entrevistados:

[...] Em grupo não tinha desvantagem porque todos trabalhavam para todos, e todos ganhavam a mesma coisa. Se trabalhar individual, se você não conseguir muito também não ganha muito. Não deu certo porque teve alguns que quiseram passar a perna.

\section{e) A relação entre ITCPS e os catadores do município de Cerro Largo}

Neste sentido, eles acreditam e estão esperançosos de que a Incubadora possa ajudá-los a iniciar uma organização que tenha sustentabilidade e conti- 
nuidade. É fato que muitos ainda não compreenderam a verdadeira função da incubadora nem como a relação entre a ITCP e os catadores se realizará ou irá funcionar. Eles ainda não compreendem exatamente qual é o papel da Incubadora, no entanto, isso revela a importância do trabalho educacional, que vai muito além da assistencial.

Parece que a Incubadora reacendeu a esperança desses trabalhadores em serem reconhecidos pela sociedade local como praticantes de um trabalho fundamental e importante para a sustentabilidade do município. Embora ainda não tenham uma compreensão completa do papel da incubadora, percebem alguns elementos importantes do papel de uma ITCP. Quando falam da Incubadora e das reuniões já realizadas, é perceptível a esperança de que ela ajudará na organização e na transparência das operações. Para exemplificar, vejamos a fala a seguir:

'A incubadora está nos ajudando a se organizar e saber que tem alguém que está nos incentivando a ir para frente'; 'é importante orientar e ensinar nós a trabalhar em grupo, para que não aconteça o que já aconteceu na outra associação'.

A partir da identificação dos cenários e dos problemas da sociedade envolvendo os catadores de resíduos sólidos urbanos, na cidade de Cerro Largo, e com vistas ao desenvolvimento da cidadania deliberativa dos agentes envolvidos nesse processo, foram elencadas algumas demandas de ações específicas a serem desenvolvidas pela ITCEES, visando a um processo de intervenção para o desenvolvimento local e regional: a realização de ações de educação ambiental junto à comunidade, a realização de uma assessoria técnica, para a constituição de uma cooperativa de catadores de resíduos sólidos urbanos, e o acompanhamento das políticas socioambientais baseadas na gestão social e na economia solidária.

A primeira ação, pautada na educação ambiental, busca soluções voltadas ao cenário atual de Cerro Largo. Além da questão ambiental, há a social, já que existem famílias que dependem da coleta de materiais recicláveis no município. As hostilidades relatadas pelos investigados só serão revertidas, ou até mesmo amenizadas, se a comunidade como um todo tiver conhecimento do papel que seus membros desempenham na sociedade atual. Isso está intimamente ligado à necessidade de atividades de educação, sensibilização e mobilização ambiental à comunidade.

A segunda ação, voltada para o apoio à constituição de uma cooperativa de catadores, faz-se importante na medida que organiza a gestão e o trabalho de uma parcela da população posta à margem do sistema de geração de emprego e renda convencional do mercado. A operacionalização dessas atividades visa ao assessoramento da cooperativa e à formação dos associados para a autogestão, além de dar suporte para o encaminhamento de projetos de gestão dos resíduos sólidos urbanos e de contribuir na averiguação das conformidades ambientais, por meio de acompanhamentos, encontros, fóruns de formação e reuniões.

E a terceira ação proposta a partir do intuito de intervenção na realidade socioeconômica ambiental segue a tendência nacional das incubadoras tecnológicas de disponibilizar suporte técnico e operacional seguindo as definições de 
normas e condutas de funcionamento no âmbito da Economia Solidária Nacional, a fim de fornecer apoio técnico ao município de Cerro Largo/RS, para a reestruturação de projetos de resíduos sólidos urbanos submetidos e/ou aprovados, visando à captação de recursos financeiros para aplicação na coleta, transporte, transbordo e triagem, armazenamento e disposição final desses resíduos.

\section{Considerações finais}

As incubadoras sociais, na condição de espaços plurais e efetivos de gestão social, propiciam aos atores em situação de vulnerabilidade que eles vislumbrem a possibilidade de serem acolhidos em um ambiente de construção de conhecimento, visando a sua organização com autonomia. Esta organização estaria assentada em princípios de cooperação, solidariedade e integração dos centros de ciência e tecnologias do país com as bases da pirâmide social. A gestão das organizações e de suas relações com as mais variadas práticas sociais de diferentes atores (governamentais, não-governamentais e do setor privado) se exprime, atualmente, na noção de Gestão Social. A emergência dessa gestão social do desenvolvimento tem ganhado um corpo prático-teórico, na medida em que se avolumam pesquisas, projetos e centros de estudos que se dedicam ao entendimento de tal objeto. Esse é um terreno mais que fértil para a aplicação dessa teoria, ainda em busca de delineamentos. Esses argumentos podem ser muito bem relacionados com a Universidade Federal da Fronteira Sul - Campus Cerro Largo -, no sentido de que, sendo um pequeno município brasileiro a ter em seu território uma universidade federal, a atuação dos saberes encontra uma relação bastante próxima com o mercado, a sociedade, o poder local e os cenários locais do município. Por meio da ITCEES, é possível, a partir de delineamentos teóricos orientados pelo conhecimento transitivo acerca da gestão social - ações práticas pautadas em um relacionamento próximo à problemática socioeconômica ambiental do município.

O grande desafio dessa ação da ITCEES - UFFS - Campus Cerro Largo, junto aos catadores de resíduos sólidos urbanos, configura-se na disparidade de saberes, de experiências e de vivências. Entender o outro e trabalhar de forma mútua para a mudança de realidades coloca-se como o objetivo na construção de novas situações, tanto em termos socioeconômicos como ambientais. Diante das colocações dos entrevistados, fica evidente que os catadores de Cerro Largo carecem de uma assistência que os ajude a superar as barreiras que estão dificultando a melhora nas condições de trabalho e, consequentemente, de vida.

As experiências anteriores relatadas pelo grupo dos catadores entrevistados deixam claro que há a necessidade de constituição de uma Associação de Catadores, mas que, para que haja sucesso, será necessário um acompanhamento que propicie condições técnicas, operacionais e de conhecimento em ferramentas de gestão, que garantam transparência e confiabilidade para todos os associados. Necessário, também, constituir instrumentos de controle e de organização que deixem claros os direitos e deveres de cada membro. Outro ponto levantado mui- 
to importante é o fato da não existência de uma política pública permanente que proporcione a inclusão desta classe trabalhadora na sociedade e que permita auxiliar no incremento da renda.

O fato é que esses catadores somente conseguirão ser ouvidos se houver uma organização coletiva entre eles. É neste momento que a incubadora será fundamental para que isso se concretize. O papel da incubadora inicialmente é o de amadurecer e conscientizar a categoria para o processo de construção dessa nova cooperativa ou associação, para que seja um processo endógeno e homogêneo, ou seja, que não seja imposta por ninguém de fora do ambiente deste grupo. O importante é que todos se convençam de que é melhor e mais eficiente trabalhar em grupo.

Posteriormente, a incubadora será o ponto de referência para a transparência e a confiabilidade, permitindo, assim, construir entre eles uma cultura cooperativa e de autogestão, que é o objetivo-fim das ICPs. Por fim, espera-se que essa relação entre a incubadora e os catadores possa de fato auxiliar na construção de uma política pública de sustentabilidade, propiciando ações de desenvolvimento para o município de Cerro Largo - RS.

\section{Referências}

ALMEIDA, V. G. Pessoas residuais e o resíduo das pessoas: uma análise do desenvolvimento mercadológico do Distrito Federal - DF. Dissertação (Mestrado em Desenvolvimento Sustentável) - Universidade de Brasília, Brasília, 2008.

BOFF, V. A. COREDE Missões - planejamento estratégico regional. Governo do Estado do Rio Grande do Sul, 2012.

BORTOLI, M. Catadores de materiais recicláveis: a construção de novos sujeitos políticos, Rev. Katálysis, Florianópolis, v. 12, p. 105-114, 2008.

BOTELHO, L. L. R. et al. Universidades Empreendedoras: panorama dos estudos brasileiros sobre o tema. In: XIII Colóquio Internacional sobre Gestão Universitária nas Américas. Buenos Aires, 2013 p. 1-15.

BOULLOSA, R.; SCHOMMER, P. C. Gestão social: caso de inovação em políticas públicas ou mais um enigma de lampedusa? In: Encontro Nacional de Pesquisadores em Gestão Social, 3., 2009, Juazeiro do Norte/Petrolina. Anais..., Juazeiro do Norte/Petrolina: NIGS/UNIVASF, 2009 , p. 65-92.

BURRELL, G.; MORGAN, G. Sociological paradigms and organisational analysis. v. 248. London: Heinemann, 1979.

CARVALHO, J. E. F. B.; CANÇADO, A. C. Gestão e Racionalidade: Análise da Metodologia de Incubação de Cooperativas Populares da ITCP/NESol/UFT. In: CANÇADO, A. C.; CANÇADO, A. C. M. G. Incubação de cooperativas populares: metodologia dos indicadores de incubação. 2. ed. Palmas: Futura, 2009.

CANÇADO, A. Fundamentos teóricos da gestão social. 246 p. Tese (Doutorado em Administração) - Universidade Federal de Lavras, Lavras, 2011. 
CARRION, R. Gestão social: especificidades e práticas em discussão. In: Silva, J. G. et al. (Org.). Tecnologias de gestão: por uma abordagem multidisciplinar. Vitória: EDUFES, 2007.

FRANÇA FILHO, G. Definindo gestão social. In: SILVA JR. et al. (Org.). Gestão social: práticas em debate, teorias em construção. Juazeiro do Norte: UFC, 2008, p. 27-36.

FISCHER, T. A gestão do desenvolvimento social: agenda em aberto e propostas de qualificação. In: Congresso Internacional DEL Clad Sobre La Reforma del Estado Y de la Administración Pública, 7, 2002, Lisboa. Anais... Lisboa: CLAD, 2002, p. 1-16.

GIL, A. C. Como elaborar projetos de pesquisa. 4. ed. São Paulo: Atlas, 2002.

5. ed. São Paulo: Atlas, 2010.

GONÇALVES, M. A. O trabalho dos catadores de resíduos recicláveis em associações e cooperativas no estado de Mato Grosso do Sul. In: VIII Seminário do Trabalho: Trabalho, Educação e Políticas Sociais no Século XXI. v. 1. p. 1-13 Marília: UNESP, 2012.

LEAL, Alzira Elaine Melo. Martha de Moraes Andrade: uma Luz... In: SEMINÁRIO DE PESQUISA EM EDUCAÇÃO DA REGIÃO SUL, 5., 2004, Curitiba. Anais eletrônicos Anped Sul 2004. Curitiba: Pontifícia Universidade Católica do Paraná, 2004. 1 CD-ROM.

GUERRA, A. C. Gestão das incubadoras tecnológicas de cooperativas populares: uma análise comparativa. 2008. Disponível em: <http://repositório.ufla.br/jspui/ handle/1/1996>.

GUIMARÃES, G. Integrar cooperativas. São Paulo: Unitrabalho. 1999.

LOPES, L. Gestão e gerenciamento integrados dos resíduos sólidos urbanos.

113 f. Dissertação (Mestrado em Geografia) - Universidade de São Paulo, São Paulo, 2006.

MERRIAM, S. B. Qualitative Research and Case Study Applications in Education. 2th ed. San Francisco: Jossey-Bass, 1998.

MILLES, M. B.; HUBERMAN, A. M. Qualitative data analysis: An expanded sourcebook. 2 ed. Thousand Oaks: Sage. 1994.

MORGAN, G. Paradigms, Metaphors, and Puzzle Solving in Organization Theory. Administrative Science Quarterly, v. 25, p. 605-622, 1980.

PEREIRA, J. R. Considerações metodológicas sobre o processo de incubação de cooperativas populares. In: CANÇADO, A. C.; PEREIRA, J. R.; SILVA JÚNIOR, J. T. Economia solidária, cooperativismo popular e autogestão: as experiências de Palmas/TO. v. 1. Palmas: NESol/UFT, 2007.

PNSB. Pesquisa Nacional de Saneamento Básico. Rio de Janeiro, 2008. 
REZENDE, G. M.; BOEIRA, S. L. A Construção do Conhecimento sobre Gestão na Incubação de Cooperativas Populares: uma Análise sob a Luz das Representações Sociais e das Tensões. In: IV Colóquio Internacional de Epistemologia e Sociologia da Ciência da Administração, Florianópolis, 2014.

SILVA, E. W.; DENARDI, M.; BERNO, M. V. Limites e possibilidades do cooperativismo para os catadores de materiais recicláveis. In: XVI Jornada de Extensão, ljuí. Anais..., 2015.

SINGER, P. Incubadoras universitárias de cooperativas: um relato a partir da experiência da USP. In: SINGER, P.; SOUZA, A. (Org.). A economia solidária no Brasil: autogestão como resposta ao desemprego. São Paulo: Cortez, 2000. p. 123-133.

TENÓRIO, F. G. (Re)Visitando o conceito de gestão social. Desenvolvimento em Questão, ljuí, v. 3, n. 5, p. 101-123, jan./jun. 2005. n. 2, 1990 .

Tem Razão a Administração? Revista de Administração Pública. v. 24, TENÓRIO, F. G. et al. Gestão social: uma perspectiva conceitual. Revista de Administração Pública, Rio de Janeiro, v. 32, n. 5, p. 7-23, set./out. 1998.

TREVISOL, J. V.; CORDEIRO, M. H.; HAAS, M. Construindo agendas e definindo rumos: I Conferência de Ensino, Pesquisa e Extensão da UFFS. 1. v. Chapecó: UFFS, 2011. (Memória). 